\title{
Modeling of Discharge Distribution in Bend of Ganga River at Varanasi
}

\author{
Manvendra Singh Chauhan*, Prabhat Kumar Singh Dikshit, Shyam Bihari Dwivedi \\ Department of Civil Engineering, Indian Institute of Technology, IIT (BHU), Varanasi, India \\ Email: "
}

Received 1 May 2015; accepted 6 June 2015; published 9 June 2015

Copyright (C) 2015 by authors and Scientific Research Publishing Inc.

This work is licensed under the Creative Commons Attribution International License (CC BY). http://creativecommons.org/licenses/by/4.0/

(c) (i) Open Access

\begin{abstract}
Dynamics of river behavior play a great role in meandering, sediment transporting, scouring, etc. of river at bend, which solely depends on hydraulics properties such as horizontal and vertical stress, spatial and temporal variation of discharge. Therefore understanding of discharge distribution of river Ganga is essential to apprehend the behavior of river cross section at bend particularly. The measurement of discharge is not very simple as there is no instrument that can measure the discharge directly, but velocity measurement at a section can be made. Velocity distribution at different cross sections at a time is also not easy with single measurement with the help of any instrument and method, so it required repetitions of the measurement. Velocity near the end of bank, top and bottom layer of natural streams is difficult to be measured, yet velocity distribution at these regions plays important role in characterizing the behavior of river. This paper deals with the new advanced discharge measurement technique and measured discharge data has been used for modelling at river bend. To carry out the distribution of discharge and velocity with depth in river Ganga, the length of river in study area was distributed into 14 different cross sections, M-1 to M-14, measured downstream to upstream and the measurement was done by using of ADCP (Acoustic Doppler Current Profiler). At each cross section, profiles were measured independently by an ADCP and data acquired from ADCP were further used for the regression modeling. A multiple linear regression model was developed, which showed a high correlation among the discharge, depth and velocity parameters with the root mean square error $\left(R^{2}\right)$ value of 0.8624 .
\end{abstract}

\section{Keywords}

ADCP, Discharge, Linear Regression, River, RMS

\section{Introduction}

Flow in open channel and a natural river is often described by simplifying cross section. But in reality cross sec-

*Corresponding author.

How to cite this paper: Chauhan, M.S., Dikshit, P.K.S. and Dwivedi, S.B. (2015) Modeling of Discharge Distribution in Bend of Ganga River at Varanasi. Computational Water, Energy, and Environmental Engineering, 4, 25-37. 
tion of river and its bend is so complicated that it needs vast practical experience to understand the hydrodynamics. On the other hand the most dangerous natural disaster, worldwide known as flood, can cause a huge economic losses as well as losses of life and livelihood. Therefore understanding the flow behavior and estimation of discharge for open channel flow (most commonly natural rivers) is very vital hence it had keen interest for the researchers for decades. Many researchers develop various methods for the discharge estimation; however, some enhance the accuracy of the previously available methods. Researcher develops regression based models [1]-[3] and some develop soft computing methods [4]-[6]. The main river flow (discharge of river) might be changed at a very large scale as human interruption takes place in term of occupying the place along the river bank or within the river basin [7]. Regression based approach is most commonly very useful for the ungauged sites for discharge estimation [8]-[10].

The increase in the flow of any river is caused by the large volume of rainfall in its basin, which would probably change the physical parameters of the river involving the changes in the depth due to bank erosion' taking place and width of flow [11]-[14]. The river hydrodynamics could directly affect the flow pattern of river and may change in river morphology. [15]-[18] observed that the meandering is one of the most common pattern followed by fluvial rivers. A lot of research work is completed by researchers for the study of bankfull discharge and bankfull velocity of river, but there is a lack of research about the natural flow and natural velocity of river.

It is to understand that, the discharge of river is a function of river meandering wavelength and amplitude, as the higher the value of river meandering wavelength and amplitude, higher will be the discharge and vice versa. The above understanding gives a way to go forward with this research in the direction that the river parameters must naturally have a relationship with each other. The main purpose of this paper is to develop a correlation among parameters of Varanasi bend of holy River Ganga which are directly related to the physical parameters of river i.e. discharge, depth and velocity. The complete measurement on the Varanasi bend was done in the month of November 2013.

With the progresses of measuring discharge and understanding behavior of Natural River, Acoustic Doppler Current Profiler (ADCP) technologies, a moving boat discharge measurement technique is gradually replacing the classic procedure using mechanical meters when the water is sufficiently deep for ADCP applications. While measuring discharge through ADCP, the transducers of an ADCP are mounted facing down and barely submerged under the water surface. They ping continuously while the boat is traversing from bank to bank. The boat motion is monitored by bottom tracking acoustic pings or by a global positioning system (GPS). The water flux crossing the vertical plane of the boat path is computed, which is the same as the river discharge. The ADCP can be used for measuring a velocity profile in the vertical when the ADCP is held at a fixed position for taking a large number of the single ping velocity measurements. The averaged single ping velocity profiles reduce the measurement errors so that a meaningful mean velocity profile can be obtained.

This paper is designed to address the following objectives by using data generated from the ADCP

- Quantify the discharge and velocity distribution for the different cross section along the bend of river Ganga

- Identify relationships between different hydraulic parameters and thus perform regression analysis. Organization of paper includes:

- an overview of the discharge measurement and regression modeling

- description of study area (Section 2)

- descriptions of the methods used (Section 3)

- the data analysis and model development (Section 4)

- discussion of the results (Section 5); and

- conclusions (Section 6).

\section{Study Area}

Varanasi $\left(25^{\circ} 20^{\prime} \mathrm{N}\right.$ and $\left.83^{\circ} 7^{\prime} \mathrm{E}\right)$ is located in the middle Ganges valley of North India, in the Eastern part of the Uttar Pradesh, along the left crescent-shaped bank of the Ganges, averaging between 50 feet $(15 \mathrm{~m})$ and 70 feet ( $21 \mathrm{~m}$ ) above the river. It is oldest city situated on the convex bank of holy River Gangaas shown in Figure 1. It is called the longest river of India, having its total length $2525 \mathrm{KM}$ from Gangotri to Ganga Sagar. Being located in the Indo-Gangetic Plains of North India, the land is very fertile because low level floods in the Ganges continually replenish the soil. Varanasi is often said to be located between two confluences: one of the Ganges and Varuna, and other of the Ganges and Assi, although the latter has always been a rivulet rather than a river. The 


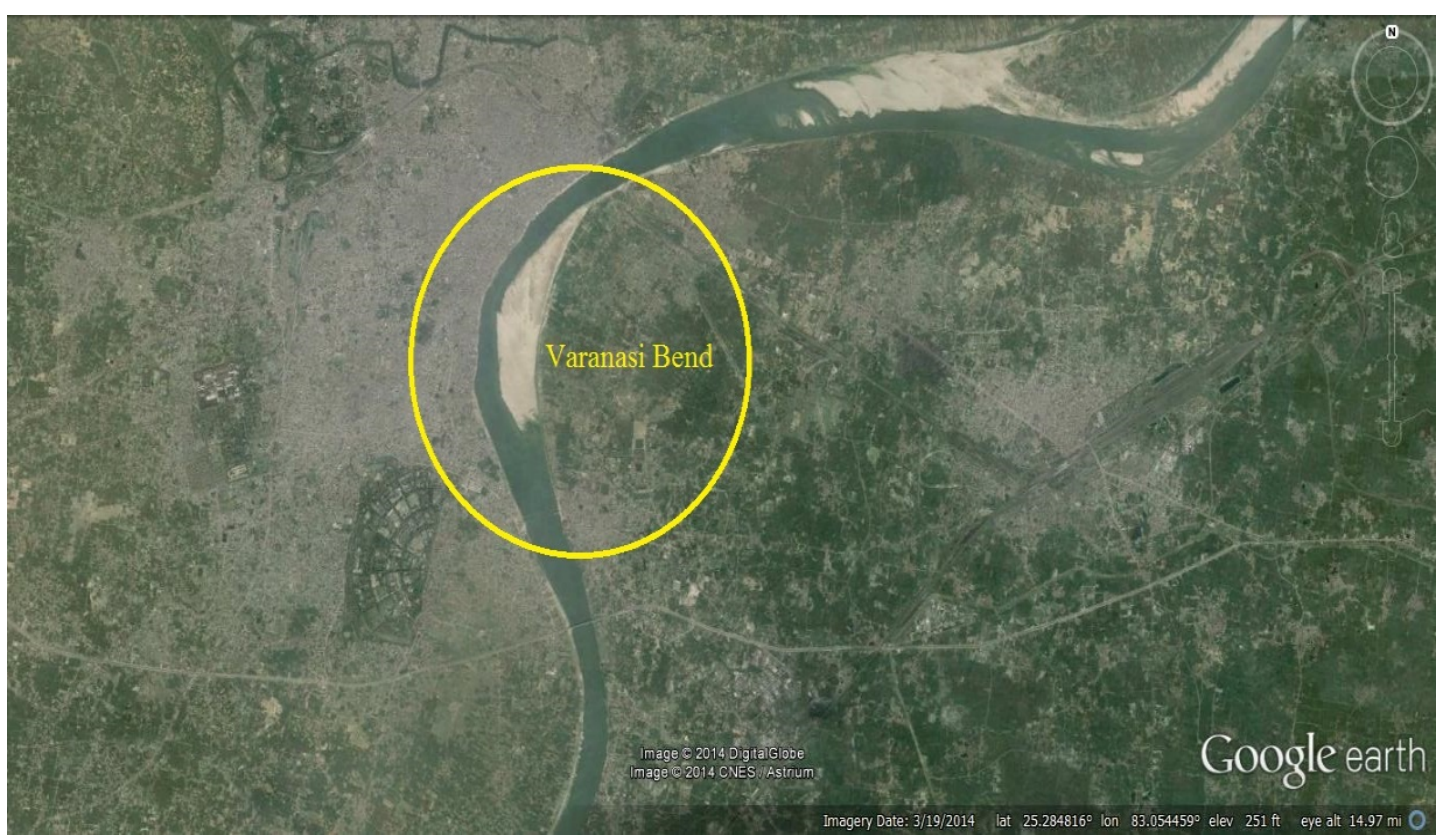

Figure 1. Study area: natural bend in river Ganga at varanasi.

distance between the two confluences is around 2.5 miles $(4.0 \mathrm{~km})$. Rarely has any river gathered in itself so much meaning and reverence as the Ganga has over three millennia in the Indian subcontinent. The land-water interface on the Ganga's banks is fashioned out of the need to access the rising and falling water levels in the monsoon and dry seasons. The cultural landscape of this interface a ghat (steps and landings) lined by temples and other public buildings, pavilions, kunds (tanks), streets and plazas is layered and kinetic, and responsive to the river's flow. At Varanasi, where the Ganga reverses its flow northwards, the ghats describe a crescent sweep in a $7.6 \mathrm{~km}$ stretch.

The climate of the city, as of Northern India on the whole, is of tropical nature with extremes of temperature, varying from a minimum of $5^{\circ} \mathrm{C}$ in winter to a maximum of $45^{\circ} \mathrm{C}$ in summer. The annual rainfall varies from $680 \mathrm{~mm}$ to $1500 \mathrm{~mm}$, with a large proportion occurring during the monsoon season, in the months of July to September.

\section{Methodology}

To achieve the objective of measuring velocity distribution and understanding the behavior of velocity distribution with depth of river in the river cross-section, an ADCP, was used. The whole study river length was divided into the 14 distinct cross-sections for discharge measurement, named as M-14 to M-1 respectively from upstream of flow to downstream of flow. Further with the help of ADCP, complete profiling for depth and discharge of each cross-section had been done. Recorded ADCP data have been extracted by using the supporting software of ADCP i.e. Win River-II, for analysis purpose. Excel sheets for each cross-section (from M-1 to M-14) of distance from bank, velocity and depth was prepared for calibration of regression based model. For preparation of data, shortest width cross-section was selected and divided it into 4 uniform parts (width wise), the width of shortest cross-section was 281 meters after dividing it, the division width was 74.25 meters, average the velocity and depth parameters of each part as V1, V2, V3, V4 \& D1, D2, D3, D4 for the cross-section M-7. The area of each part was also calculated by using AutoCAD software termed as A1, A2, A3, and A4 respectively.

Similarly by applying this process on all the data of each cross-section from M1 to M14 was estimated and listed in Table 1. M-1 has been divided into 7 parts having the average velocity from V1 to V7, average depth from D1 to D7 and the area from A1 to A7 and Cross-sectional view with reduced level is also shown in Figure 2, M-2 has been divided into 6 parts having the average velocity from V1 to V6, average depth from D1 to D6 and the area from A1 to A6, M-3 has been divided into 5 parts having the average velocity from V1 to V5, 
Table 1. Description of cross sectional data.

\begin{tabular}{|c|c|c|c|c|c|c|c|c|c|}
\hline Sr. No. & $\begin{array}{c}\text { Profile } \\
\text { No. }\end{array}$ & $\begin{array}{l}\text { Total } \\
\text { Width } \\
\text { in (m) }\end{array}$ & $\begin{array}{c}\text { No. of } \\
\text { Division }\end{array}$ & $\begin{array}{c}\text { Name of } \\
\text { Average } \\
\text { Depths }\end{array}$ & $\begin{array}{l}\text { Average Depth } \\
\text { in (m)/74.25 m } \\
\text { width }\end{array}$ & $\begin{array}{c}\text { Name of } \\
\text { Average } \\
\text { Velocities }\end{array}$ & $\begin{array}{c}\text { Average } \\
\text { Velocity in } \\
\text { (m)/74.25 m } \\
\text { width }\end{array}$ & $\begin{array}{c}\text { Area of } \\
\text { each divided } \\
\text { section in } \mathbf{m}^{2}\end{array}$ & $\begin{array}{l}\text { Discharge } \\
\text { at each } \\
\text { cross section }\end{array}$ \\
\hline \multirow{7}{*}{1} & \multirow{7}{*}{ M-1 } & \multirow{7}{*}{460} & \multirow{7}{*}{6.1953} & D1 & 11.16 & V1 & 0.113 & 1116.6769 & 126.18449 \\
\hline & & & & D2 & 19.98 & V2 & 0.221 & 1475.8199 & 326.1562 \\
\hline & & & & D3 & 18.11 & V3 & 0.3 & 1351.3572 & 405.40716 \\
\hline & & & & D4 & 16.53 & V4 & 0.34 & 1228.3031 & 417.62305 \\
\hline & & & & D5 & 11.07 & V5 & 0.34 & 830.8381 & 282.48495 \\
\hline & & & & D6 & 6.95 & V6 & 0.14 & 526.488 & 73.70832 \\
\hline & & & & D7 & 4.82 & V7 & 0.08 & 15.2103 & 1.216824 \\
\hline \multirow{6}{*}{2} & \multirow{6}{*}{ M-2 } & \multirow{6}{*}{434} & \multirow{6}{*}{5.8451} & D1 & 9 & V1 & 0.192 & 879.809 & 168.92333 \\
\hline & & & & D2 & 15.72 & V2 & 0.43 & 1163.7889 & 500.42923 \\
\hline & & & & D3 & 14.62 & V3 & 0.371 & 1094.5191 & 406.06659 \\
\hline & & & & D4 & 12.98 & V4 & 0.252 & 967.9261 & 243.91738 \\
\hline & & & & D5 & 9.7 & V5 & 0.163 & 731.0454 & 119.1604 \\
\hline & & & & D6 & 5.58 & V6 & 0.098 & 210.2677 & 20.606235 \\
\hline \multirow{5}{*}{3} & \multirow{5}{*}{ M-3 } & \multirow{5}{*}{357} & \multirow{5}{*}{4.8081} & D1 & 15.44 & V1 & 0.32 & 1226.6425 & 392.5256 \\
\hline & & & & D2 & 18.22 & V2 & 0.29 & 1349.0814 & 391.23361 \\
\hline & & & & D3 & 14.97 & V3 & 0.3 & 1112.5433 & 333.76299 \\
\hline & & & & D4 & 12.86 & V4 & 0.22 & 950.3806 & 209.08373 \\
\hline & & & & D5 & 6.8 & V5 & 0.17 & 391.39 & 66.5363 \\
\hline \multirow{5}{*}{4} & \multirow{5}{*}{ M-4 } & \multirow{5}{*}{378} & \multirow{5}{*}{5.0909} & D1 & 15.1 & V1 & 0.173 & 1271.3793 & 219.94862 \\
\hline & & & & D2 & 16.31 & V2 & 0.489 & 1204.4832 & 588.99228 \\
\hline & & & & D3 & 12.52 & V3 & 0.507 & 931.5344 & 472.28794 \\
\hline & & & & D4 & 11.06 & V4 & 0.295 & 821.6697 & 242.39256 \\
\hline & & & & D5 & 7.62 & V5 & 0.097 & 560.2798 & 54.347141 \\
\hline \multirow{5}{*}{5} & \multirow{5}{*}{ M-5 } & \multirow{5}{*}{386} & \multirow{5}{*}{5.1987} & D1 & 8.57 & V1 & 0.122 & 864.4567 & 105.46372 \\
\hline & & & & D2 & 17.87 & V2 & 0.479 & 1323.7853 & 634.09316 \\
\hline & & & & D3 & 15.75 & V3 & 0.537 & 1170.9607 & 628.8059 \\
\hline & & & & D4 & 15.41 & V4 & 0.248 & 1144.988 & 283.95702 \\
\hline & & & & D5 & 8.31 & V5 & 0.101 & 661.7477 & 66.836518 \\
\hline \multirow{4}{*}{6} & \multirow{4}{*}{ M-6 } & \multirow{4}{*}{297} & \multirow{4}{*}{4} & D1 & 13.88 & V1 & 0.504 & 1054.9663 & 531.70302 \\
\hline & & & & D2 & 13.1 & V2 & 0.641 & 1062.1626 & 680.84623 \\
\hline & & & & D3 & 12.71 & V3 & 0.313 & 949.9967 & 297.34897 \\
\hline & & & & D4 & 6.51 & V4 & 0.137 & 488.8122 & 66.967271 \\
\hline
\end{tabular}


M. S. Chauhan et al.

\section{Continued}

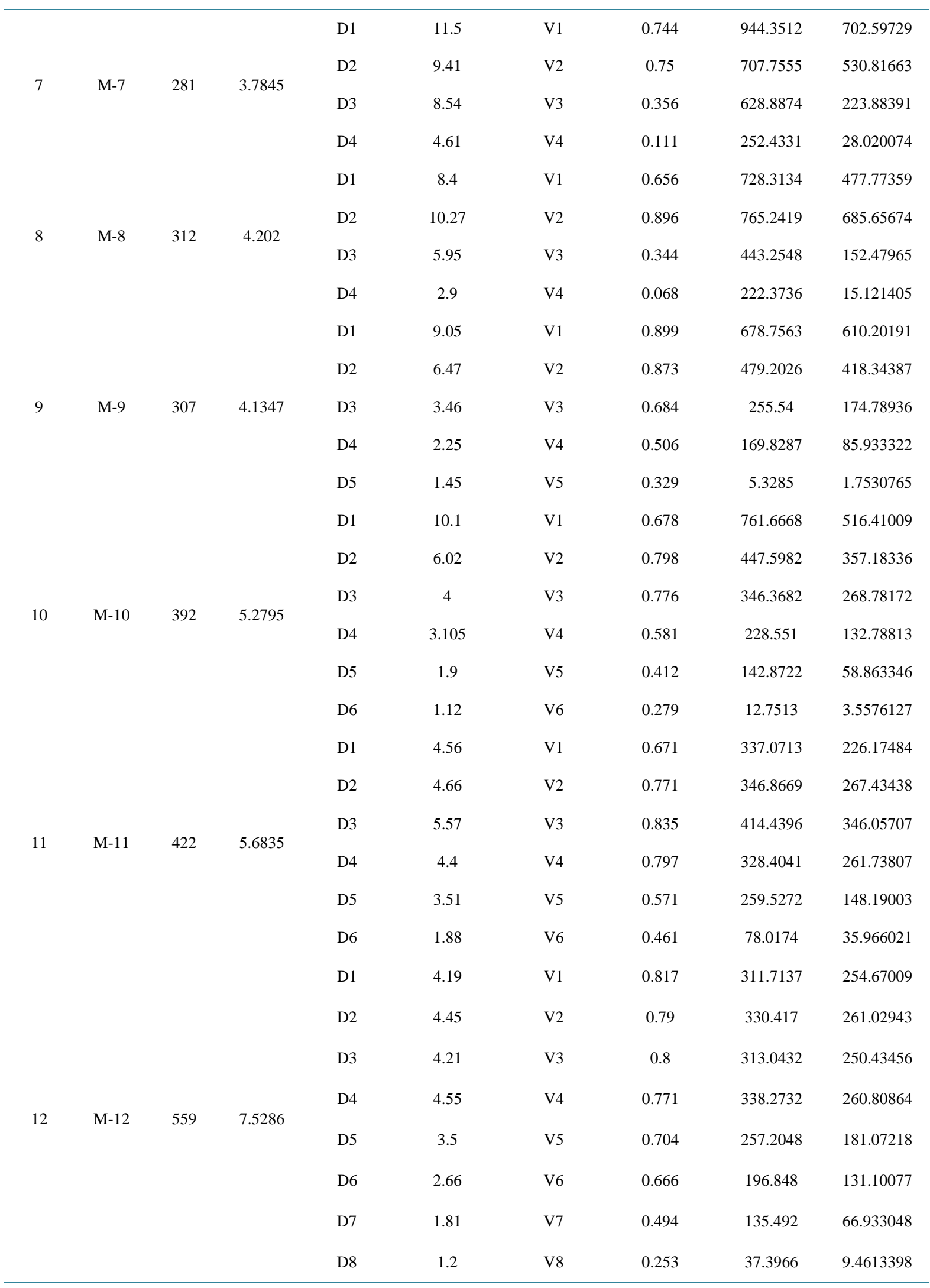




\section{Continued}

\begin{tabular}{|c|c|c|c|c|c|c|c|c|c|}
\hline & & & & D1 & 3.74 & V1 & 0.524 & 279.8455 & 146.63904 \\
\hline & & & & D2 & 4.48 & V2 & 0.56 & 332.7477 & 186.33871 \\
\hline & & & & D3 & 5.92 & V3 & 0.526 & 436.2374 & 229.46087 \\
\hline & & & & D4 & 6.12 & V4 & 0.516 & 453.295 & 233.90022 \\
\hline & & & & D5 & 4.48 & V5 & 0.521 & 333.9429 & 173.98425 \\
\hline \multirow[t]{11}{*}{13} & M-13 & 814 & 10.963 & D6 & 3.48 & V6 & 0.497 & 255.3419 & 126.90492 \\
\hline & & & & D7 & 2.27 & V7 & 0.484 & 170.2859 & 82.418376 \\
\hline & & & & D8 & 1.84 & V8 & 0.534 & 135.8387 & 72.537866 \\
\hline & & & & D9 & 2.2 & V9 & 0.436 & 163.9797 & 71.495149 \\
\hline & & & & D10 & 2.42 & V10 & 0.356 & 179.3759 & 63.85782 \\
\hline & & & & D11 & 2.38 & V11 & 0.314 & 152.1876 & 47.786906 \\
\hline & & & & D1 & 7.82 & V1 & 0.287 & 594.5108 & 170.6246 \\
\hline & & & & D2 & 7.566 & V2 & 0.319 & 560.7728 & 178.88652 \\
\hline & & & & D3 & 5.27 & V3 & 0.337 & 392.2132 & 132.17585 \\
\hline & & & & D4 & 3.71 & V4 & 0.357 & 274.2688 & 97.913962 \\
\hline & & & & D5 & 3.95 & V5 & 0.354 & 291.6898 & 103.25819 \\
\hline \multirow{5}{*}{14} & M-14 & 694 & 9.3468 & D6 & 4.14 & V6 & 0.46 & 307.0175 & 141.22805 \\
\hline & & & & D7 & 5.21 & V7 & 0.459 & 386.965 & 177.61694 \\
\hline & & & & D8 & 5.72 & V8 & 0.455 & 424.994 & 193.37227 \\
\hline & & & & D9 & 5.48 & V9 & 0.43 & 410.8616 & 176.67049 \\
\hline & & & & D10 & 4.5 & V10 & 0.39 & 102.7781 & 40.083459 \\
\hline
\end{tabular}

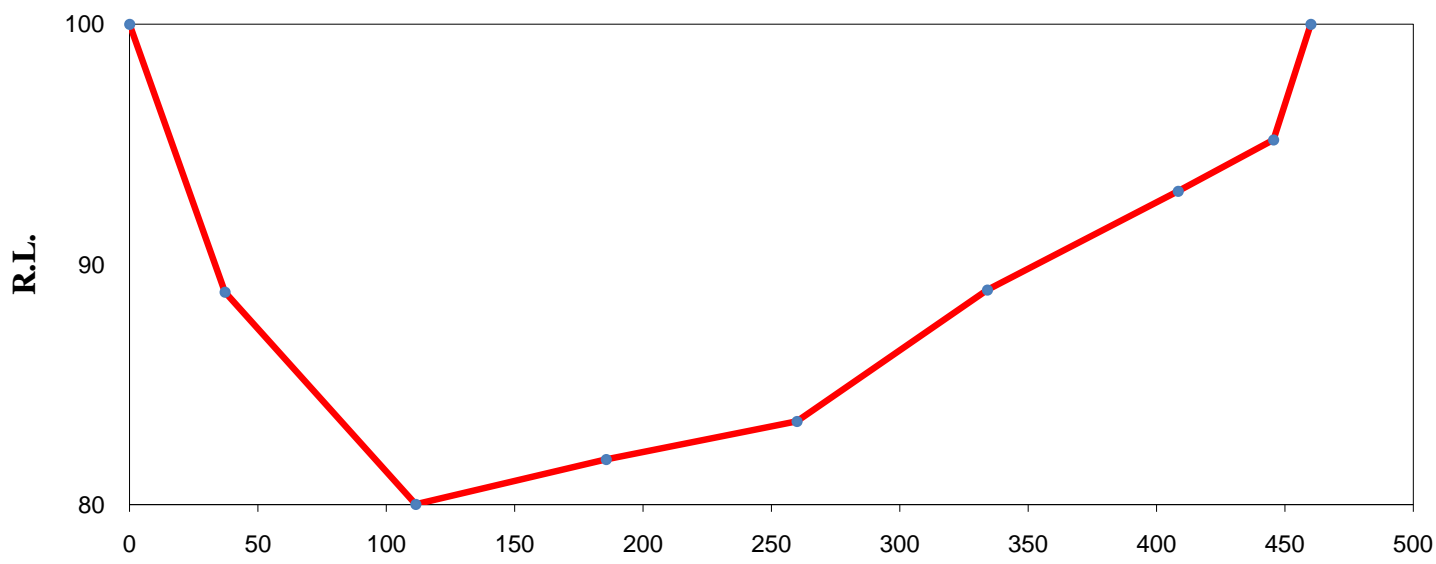

Distance from bank (m)

Figure 2. Typical behavior of river cross section w.r.t. Reduced Level (R.L.) at M-1. 
average depth from D1 to D5 and the area from A1 to A5, M-4 has been divided into 5 parts having the average velocity from V1 to V5, average depth from D1 to D5 and the area from A1 to A5, M-5 has been divided into 5 parts having the average velocity from V1 to V5, average depth from D1 to D5 and the area from A1 to A5, M-6 has been divided into 4 parts having the average velocity from V1 to V4, average depth from D1 to D4 and the area from A1 to A4, M-8 has been divided into 4 parts having the average velocity from V1 to V4,average depth from D1 to D4 and the area from A1 to A4, M-9 has been divided into 5 parts having the average velocity from V1 to V5, average depth from D1 to D5 and the area from A1 to A5, M-10 has been divided into 6 parts having the average velocity from V1 to V6,average depth from D1 to D6 and the area from A1 to A6, M-11 has been divided into 6 parts having the average velocity from V1 to V6,average depth from D1 to D6 and the area from A1 to A6, M-12 has been divided into 8 parts having the average velocity from V1 to V8, average depth from D1 to D8 and the area from A1 to A8, M-13 has been divided into 11 parts having the average velocity from V1 to V11, average depth from D1 to D11 and the area from A1 to A11, M-14 has been divided into 10 parts having the average velocity from V1 to V10, average depth from D1 to D10 and the area from A1 to A10.

\section{Data Analysis and Modeling}

\section{a) Data Analysis}

Before the development of the models of regression, it is the most important to check whether the variables in data have any correlation or not. Therefore, each cross-sectional data of discharge, depth and velocity are checked for the multiple regression, the $\mathrm{R}^{2}$, Adjusted $\mathrm{R}^{2}$, Standard error of estimates, standard error, $\mathrm{t}$ value and $\mathrm{p}$ value for each cross-section are listed in Table 2 which shows there is a strong correlation between discharge, depth and velocity data, this analysis gives an clear idea to develop a multiple linear regression model.

$\mathrm{R}$-squared $\left(\mathrm{R}^{2}\right)$ is a statistical measure of how close the data are to the fitted regression line. It is also known as the coefficient of determination, or the coefficient of multiple determinations for multiple regressions. The value $\left(\mathrm{R}^{2}\right)$ should always between $0 \%$ and $100 \%$ :

- $0 \%$ indicates that the model explains none of the variability of the response data around its mean.

- $100 \%$ indicates that the model explains all the variability of the response data around its mean.

For any regression model first indicator of generalizability is the adjusted $\left(\mathrm{R}^{2}\right)$ value, which is adjusted for the number of variables included in the regression equation. This is used to estimate the expected shrinkage in $\left(\mathrm{R}^{2}\right)$ that would not generalize to the variable because our solution is over-fitted to the data set by including too many independent variables. If the adjusted $\left(\mathrm{R}^{2}\right)$ value is much lower than the $\left(\mathrm{R}^{2}\right)$ value, it is an indication that our regression equation may be over-fitted to the sample, and of limited generalizability.

The $\mathrm{R}^{2}$ method is a useful linear regression tool for exploratory model building as it assists in finding subsets of independent variables that best predict a dependent variable in a given sample (SAS Institute, Inc., 1994). This algorithm examines all of the possible combinations of the independent variables and ranks them according to decreasing order of $\mathrm{R}^{2}$ (fraction of the variance explained by the regression) magnitude for the given sample. Using this output of ranked $\mathrm{R}^{2}$, the best combination of independent variables was selected for further testing for inclusion in the final regression equations. The type of regression equation that is most suitable to describe the relation depends naturally on the variables considered and with respect to hydrology on the physics of the processes driving the variables. Furthermore, it also depends on the range of the data one is interested in.

\section{b) Development of Regression Models}

(i) Multiple Regression model for 8 Cross-Sections: For development of the regression model, the complete data set of all cross-section were analyzed separately. Three cross-sections from both ends of the bend and two cross-sections from center location have been selected for model development (as shown in Figure 3). Selected cross-section gives a complete picture of the Varanasi bend of River Ganga. For calibration of the regression model complete 55 data (about $65 \%$ of total) and remaining 31 data (about $35 \%$ of total) are used for the validation of the model. As shown in the Table 3 the value of $R^{2}$ is 0.8674 of the calibrated model which shown a strong correlation between discharge, depth and velocity data of the complete data set.

Thus developed discharge equation from regression analysis is $\mathbf{Q}=\mathbf{Y}_{\mathbf{0}}+\mathbf{a} \times \mathbf{V}+\mathbf{b} \times \mathbf{D}$, where $\mathbf{Q}$ is Discharge $\mathrm{V}$ is Velocity and $\mathrm{D}$ is depth, $\mathrm{Y}_{\mathrm{o}}$, a and $\mathrm{b}$ are constants which has to determined by regression analysis.

(ii) Partial regression model: For analyzing the fact that whether the discharge is more dependent on which parameter, depth or velocity, a partial regression model has been studied by keeping depth and velocity constant. For the modeling purpose (keeping depth constant) the data had shorted in a manner that the depth ranging in 
Table 2. Cross-sectional data analysis.

\begin{tabular}{|c|c|c|c|c|c|c|c|c|c|c|c|}
\hline Sr. No. & C-S & $\mathbf{R}$ & $\mathbf{R}^{2}$ & $\operatorname{Adj}^{2}$ & $Y_{0}$ & a & b & SEE & $t$ & $\mathbf{P}$ & Std Error \\
\hline \multirow{4}{*}{1} & & & & & & & & & -4.72 & 0.01 & 29.66 \\
\hline & M-1 & 0.9892 & 0.9784 & 0.9677 & -140.1343 & 823.845 & 14.8447 & 28.9603 & 5.87 & 0.00 & 140.24 \\
\hline & & & & & & & & & 5.51 & 0.01 & 2.69 \\
\hline & & & & & & & & & -3.37 & 0.04 & 31.52 \\
\hline \multirow[t]{3}{*}{2} & M-2 & 0.9973 & 0.9946 & 0.991 & -106.0717 & 1451.219 & -2.2241 & 16.7843 & 7.15 & 0.01 & 202.95 \\
\hline & & & & & & & & & -0.33 & 0.76 & 6.72 \\
\hline & & & & & & & & & -12.73 & 0.01 & 18.22 \\
\hline \multirow[t]{3}{*}{3} & M-3 & 0.999 & 0.9981 & 0.9961 & -232.0105 & 1086.547 & 16.5426 & 8.4102 & 7.77 & 0.02 & 139.79 \\
\hline & & & & & & & & & 8.06 & 0.02 & 2.05 \\
\hline & & & & & & & & & -3.45 & 0.07 & 54.18 \\
\hline \multirow[t]{3}{*}{4} & M-4 & 0.995 & 0.9901 & 0.9802 & -187.1077 & 892.8937 & 17.3317 & 28.7211 & 9.54 & 0.01 & 93.58 \\
\hline & & & & & & & & & 3.46 & 0.07 & 5.01 \\
\hline & & & & & & & & & -2.38 & 0.14 & 54.09 \\
\hline \multirow[t]{3}{*}{5} & M-5 & 0.9974 & 0.9948 & 0.9896 & -128.5444 & 1178.466 & 9.0698 & 27.8852 & 8.24 & 0.01 & 142.98 \\
\hline & & & & & & & & & 1.40 & 0.30 & 6.50 \\
\hline & & & & & & & & & -4.41 & 0.14 & 27.67 \\
\hline \multirow[t]{3}{*}{6} & M-6 & 0.9997 & 0.9993 & 0.9979 & -121.947 & 1170.01 & 4.4053 & 12.27 & 20.82 & 0.03 & 56.20 \\
\hline & & & & & & & & & 1.21 & 0.44 & 3.65 \\
\hline & & & & & & & & & -1.03 & 0.49 & 253.87 \\
\hline \multirow[t]{3}{*}{7} & M-7 & 0.9785 & 0.9576 & 0.8727 & -261.565 & 587.393 & 40.15 & 106.93 & 1.23 & 0.44 & 479.24 \\
\hline & & & & & & & & & 0.77 & 0.58 & 51.99 \\
\hline & & & & & & & & & 2.84 & 0.22 & 97.24 \\
\hline \multirow[t]{3}{*}{8} & M-8 & 0.9994 & 0.9988 & 0.9964 & 275.978 & 2038.62 & -137.83 & 18.05 & 6.18 & 0.10 & 329.67 \\
\hline & & & & & & & & & -3.69 & 0.17 & 37.36 \\
\hline & & & & & & & & & -10.03 & 0.01 & 12.59 \\
\hline \multirow[t]{3}{*}{9} & M-9 & 0.9998 & 0.9997 & 0.9994 & -126.307 & 78.1056 & 73.449 & 6.3376 & 2.31 & 0.15 & 33.87 \\
\hline & & & & & & & & & 28.23 & 0.00 & 2.60 \\
\hline & & & & & & & & & -5.64 & 0.01 & 23.44 \\
\hline \multirow[t]{3}{*}{10} & M-10 & 0.9976 & 0.9953 & 0.9921 & -132.187 & 258.619 & 46.329 & 17.09 & 5.26 & 0.01 & 49.13 \\
\hline & & & & & & & & & 14.97 & 0.00 & 3.09 \\
\hline & & & & & & & & & -12.53 & 0.00 & 16.27 \\
\hline \multirow[t]{3}{*}{11} & M-11 & 0.999 & 0.9979 & 0.9965 & -203.784 & 306.824 & 50.422 & 6.3165 & 5.72 & 0.01 & 53.61 \\
\hline & & & & & & & & & 8.21 & 0.00 & 6.14 \\
\hline & & & & & & & & & -12.60 & $<0.0001$ & 6.96 \\
\hline \multirow[t]{3}{*}{12} & M-12 & 0.9992 & 0.9984 & 0.9978 & -87.7579 & 53.9182 & 69.184 & 4.6753 & 2.00 & 0.10 & 26.95 \\
\hline & & & & & & & & & 16.86 & $<0.0001$ & 4.10 \\
\hline & & & & & & & & & -14.09 & $<0.0001$ & 7.36 \\
\hline \multirow[t]{3}{*}{13} & M-13 & 0.9988 & 0.9976 & 0.9969 & -103.664 & 202.286 & 37.935 & 3.7203 & 11.52 & $<0.0001$ & 17.55 \\
\hline & & & & & & & & & 41.81 & $<0.0001$ & 0.91 \\
\hline & & & & & & & & & -2.86 & 0.02 & 55.97 \\
\hline \multirow[t]{2}{*}{14} & M-14 & 0.9201 & 0.8465 & 0.8026 & -159.944 & 244.71 & 28.683 & 17.493 & 2.36 & 0.05 & 103.59 \\
\hline & & & & & & & & & 6.19 & 0.00 & 4.63 \\
\hline
\end{tabular}

C-S: cross-section; R: Correlation constant; $\mathrm{R}^{2}$ : square of the correlation constant; Adj $\mathrm{R}^{2}$ : adjusted value of $\mathrm{R}^{2}$, $\mathrm{Y}_{\mathrm{o}}$, a and $\mathrm{b}$ are the intercept constants; SEE: Standard error of estimate, t: test value for each constants; p: test value for each constants and Std Error: standard error for each constants. 


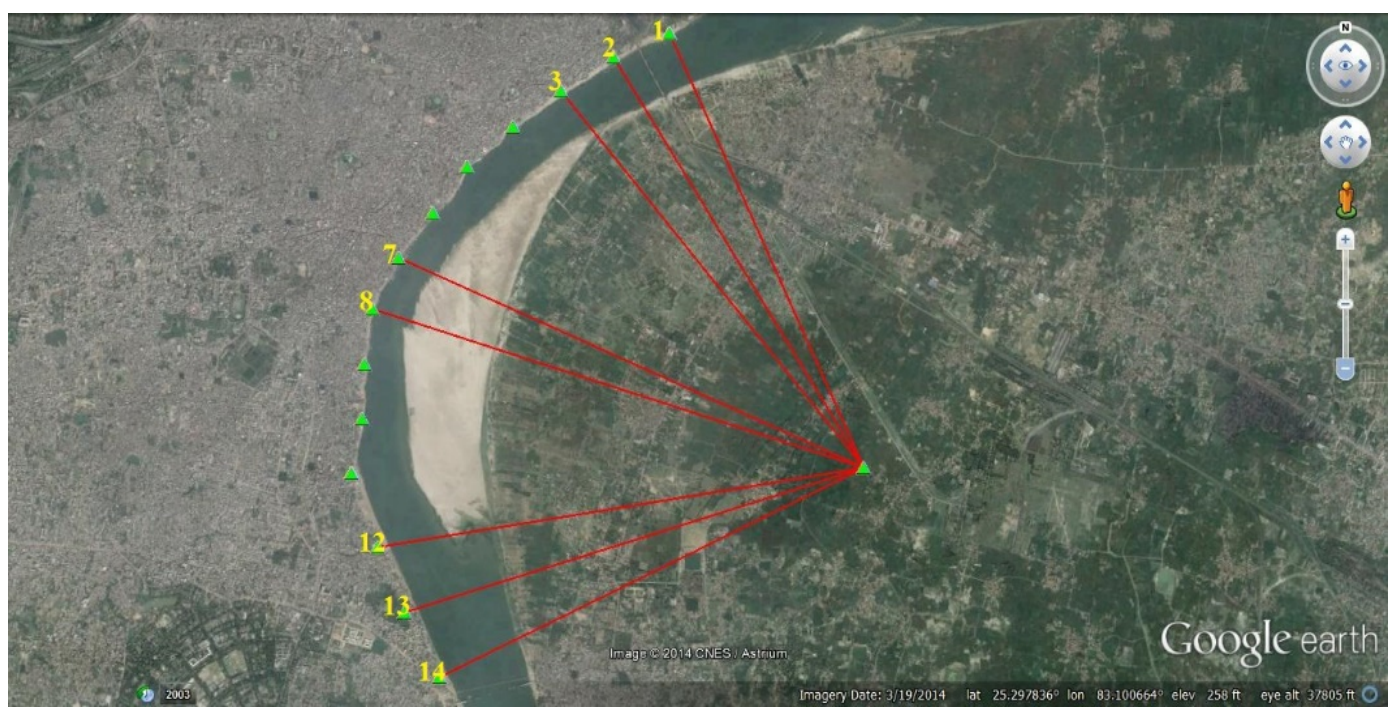

Figure 3. Bifurcation of cross-sections at Varanasi Bend of River Ganga.

Table 3. Statistical parameters of the calibrated model.

\begin{tabular}{|c|c|c|c|c|c|c|c|c|c|c|}
\hline Profile & $\mathbf{R}$ & Rsqr & AdjRsqr & $\mathbf{Y}_{\mathbf{o}}$ & $\mathbf{a}$ & b & SEE & t & $\mathbf{P}$ & Std Error \\
\hline \multirow{3}{*}{ 8-C-S } & \multirow{3}{*}{0.934} & \multirow{3}{*}{0.8723} & \multirow{3}{*}{0.8674} & \multirow{3}{*}{-205.169} & \multirow{3}{*}{519.233} & \multirow{3}{*}{27.3198} & \multirow{3}{*}{59.0513} & -8.5517 & $<0.0001$ & 23.9917 \\
\hline & & & & & & & & 13.1601 & $<0.0001$ & 39.4551 \\
\hline & & & & & & & & 16.096 & $<0.0001$ & 1.6973 \\
\hline
\end{tabular}

$1 \mathrm{~m}-5 \mathrm{~m}, 5 \mathrm{~m}-10 \mathrm{~m}, 13 \mathrm{~m}-15 \mathrm{~m}$ and finally $15 \mathrm{~m}-20 \mathrm{~m}$, the model gives the $\mathrm{R}^{2}$ value as follows 0.816 , $0.802,0.947$ and 0.966 respectively. For the model (keeping velocity constant) average the velocity in previously shorted data, it ranged up to $0.3168 \mathrm{~m} / \mathrm{s}, 0.3645 \mathrm{~m} / \mathrm{s}$ and $0.5 \mathrm{~m} / \mathrm{s}$, the model gives the $\mathrm{R}^{2}$ value as follows 0.897, 0.998 and 0.988 respectively as listed in Table 4 below. These values concluded that the discharge is more depending upon the depth of the flow as the $\mathrm{R}^{2}$ value for the model when velocity is constant is more except once i.e. 0.897 .

c) Validation of Model

From whole data set remaining 31 data used for the validation of the model. The detailed calculation for each data is shown in Table 5. From this it is clearly noticeable that at very low discharge values, depth below $5 \mathrm{~m}$ and low velocities, the model doesn't works properly and it gives unreasoned results.

\section{Result and Discussion}

River hydraulics is quite complex in natural channels and rivers. For practical and engineering purposes, the flows in river channel are often characterized by depth averaged or cross-sectional averaged properties. While these simplifications might be justifiable and necessary for practical reasons, it is important to be cognizant about the complex nature of the three-dimensional free-surface flows in rivers and open channels. A better understanding of the hydraulic properties in natural rivers would give rise to a more accurate approximation in practical applications. In this study, the velocity distribution in a river cross-section has been investigated in detail.

Also as we know that atmospheric and human intervention affects the hydrology of any area which influences the flow behavior of river. To understand these effects on main governing parameters of hydraulics on river flow characteristics, 14 different cross section shad marked along the river which lies between $7500 \mathrm{~m}$. The river flow velocity, width and depth has been computed and plotted to compare each other and identified their relationship among the above said parameters. The results showed that river depth is almost having increasing trend except the cross section (M-2), second last from downstream as clearly shown in Figure 4(a). 
Table 4. Statistical parameters of the partial regression model.

\begin{tabular}{|c|c|c|c|c|c|c|c|c|}
\hline Sr. No. & $\mathbf{R}^{2}$ & Std. deviation & MSE & RMSE & $\mathbf{Y}_{\mathbf{o}}$ & A & Range & $\begin{array}{c}\text { Constant Parame- } \\
\text { ter }\end{array}$ \\
\hline 1 & 0.816 & 36.261 & 1205.293 & 34.717 & -44.442 & 342.204 & $1-5 m$ & \multirow{4}{*}{ Depth } \\
\hline 2 & 0.802 & 59.932 & 3169.251 & 56.296 & -35.172 & 633.193 & $5-10 m$ & \\
\hline 3 & 0.947 & 53.104 & 2115.015 & 45.989 & 62.655 & 769.011 & $10-15$ m & \\
\hline 4 & 0.966 & 11.597 & 89.657 & 9.469 & 150.237 & 805.866 & $15-20 \mathrm{~m}$ & \\
\hline 5 & 0.897 & 45.307 & 1824.616 & 42.716 & -60.380 & 22.605 & $0.3168 \mathrm{~m} / \mathrm{s}$ & \multirow{3}{*}{ Velocity } \\
\hline 6 & 0.998 & 5.656 & 25.593 & 5.059 & 1.750 & 25.202 & $0.3645 \mathrm{~m} / \mathrm{s}$ & \\
\hline 7 & 0.988 & 17.128 & 234.689 & 15.320 & 19.174 & 28.876 & $0.5 \mathrm{~m} / \mathrm{s}$ & \\
\hline
\end{tabular}

Table 5. Discharge data for validation of model.

\begin{tabular}{|c|c|c|c|c|c|c|c|}
\hline Sr. No. & Velocity & Depth & Observed Discharge & A $\times$ Velocity & B $\times$ Depth & Modeled discharge & $\%$ error \\
\hline 1 & 0.173 & 15.1 & 219.9486189 & 89.827309 & 412.529 & 297.186989 & 35.11655 \\
\hline 2 & 0.489 & 16.31 & 588.9922848 & 253.904937 & 445.5859 & 494.321575 & -16.0733 \\
\hline 3 & 0.507 & 12.52 & 472.2879408 & 263.251131 & 342.0439 & 400.125727 & -15.2793 \\
\hline 4 & 0.295 & 11.06 & 242.3925615 & 153.173735 & 302.157 & 250.161423 & 3.205074 \\
\hline 5 & 0.097 & 7.62 & 54.3471406 & 50.365601 & 208.1769 & 53.373177 & -1.79212 \\
\hline 6 & 0.122 & 8.57 & 105.4637174 & 63.346426 & 234.1307 & 92.307812 & -12.4743 \\
\hline 7 & 0.479 & 17.87 & 634.0931587 & 248.712607 & 488.2048 & 531.748133 & -16.1404 \\
\hline 8 & 0.537 & 15.75 & 628.8058959 & 278.828121 & 430.2869 & 503.945671 & -19.8567 \\
\hline 9 & 0.248 & 15.41 & 283.957024 & 128.769784 & 420.9981 & 344.598602 & 21.3559 \\
\hline 10 & 0.101 & 8.31 & 66.8365177 & 52.442533 & 227.0275 & 74.300771 & 11.16793 \\
\hline 11 & 0.504 & 13.88 & 531.7030152 & 261.693432 & 379.1988 & 435.722956 & -18.0514 \\
\hline 12 & 0.641 & 13.1 & 680.8462266 & 332.828353 & 357.8894 & 485.548433 & -28.6846 \\
\hline 13 & 0.313 & 12.71 & 297.3489671 & 162.519929 & 347.2347 & 304.585287 & 2.433612 \\
\hline 14 & 0.137 & 6.51 & 66.9672714 & 71.134921 & 177.8519 & 43.817519 & -34.5688 \\
\hline 15 & 0.899 & 9.05 & 610.2019137 & 466.790467 & 247.2442 & 508.865357 & -16.6071 \\
\hline 16 & 0.873 & 6.47 & 418.3438698 & 453.290409 & 176.7591 & 424.880215 & 1.562434 \\
\hline 17 & 0.684 & 3.46 & 174.78936 & 355.155372 & 94.52651 & 244.51258 & 39.88985 \\
\hline 18 & 0.506 & 2.25 & 85.9333222 & 262.731898 & 61.46955 & 119.032148 & 38.51687 \\
\hline 19 & 0.329 & 1.45 & 1.7530765 & 170.827657 & 39.61371 & 5.272067 & 200.7323 \\
\hline 20 & 0.678 & 10.1 & 516.4100904 & 352.039974 & 275.93 & 422.800654 & -18.127 \\
\hline 21 & 0.798 & 6.02 & 357.1833636 & 414.347934 & 164.4652 & 373.64383 & 4.608408 \\
\hline 22 & 0.776 & 4 & 268.7817232 & 402.924808 & 109.2792 & 307.034708 & 14.23199 \\
\hline 23 & 0.581 & 3.105 & 132.788131 & 301.674373 & 84.82798 & 181.333052 & 36.55818 \\
\hline 24 & 0.412 & 1.9 & 58.8633464 & 213.923996 & 51.90762 & 60.662316 & 3.05618 \\
\hline 25 & 0.279 & 1.12 & 3.5576127 & 144.866007 & 30.59818 & -29.705117 & -934.973 \\
\hline 26 & 0.671 & 4.56 & 226.1748423 & 348.405343 & 124.5783 & 267.814331 & 18.41031 \\
\hline 27 & 0.771 & 4.66 & 267.4343799 & 400.328643 & 127.3103 & 322.469611 & 20.57897 \\
\hline 28 & 0.835 & 5.57 & 346.057066 & 433.559555 & 152.1713 & 380.561541 & 9.970747 \\
\hline 29 & 0.797 & 4.4 & 261.7380677 & 413.828701 & 120.2071 & 328.866521 & 25.64719 \\
\hline 30 & 0.571 & 3.51 & 148.1900312 & 296.482043 & 95.8925 & 187.205241 & 26.32782 \\
\hline 31 & 0.461 & 1.88 & 35.9660214 & 239.366413 & 51.36122 & 85.558337 & 137.8866 \\
\hline
\end{tabular}




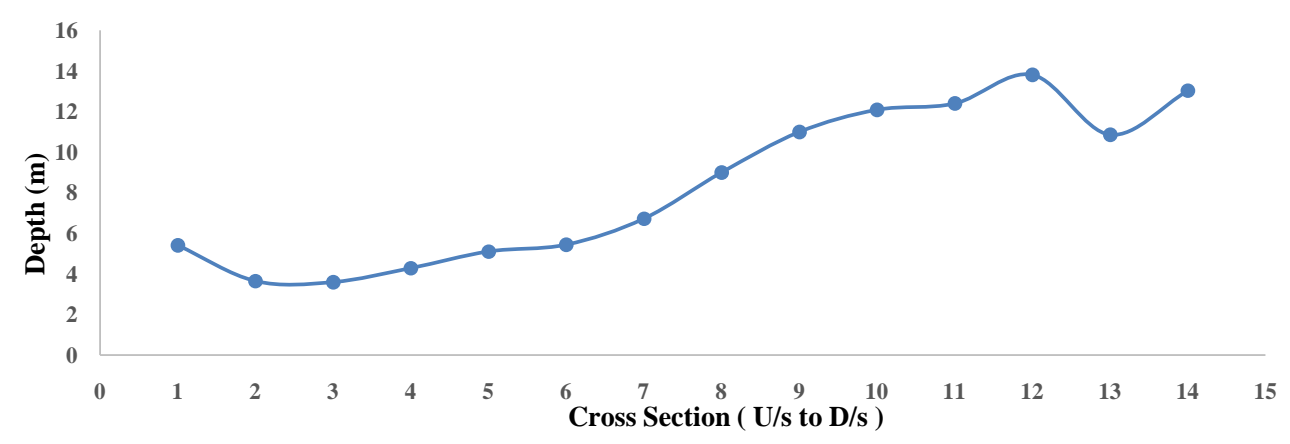

(a)

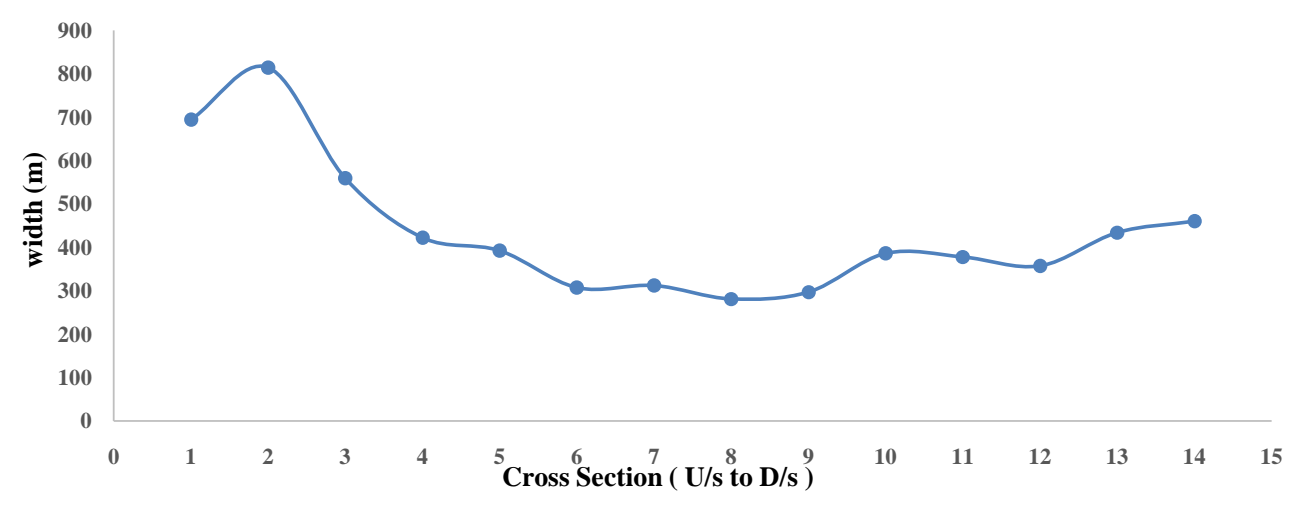

(b)

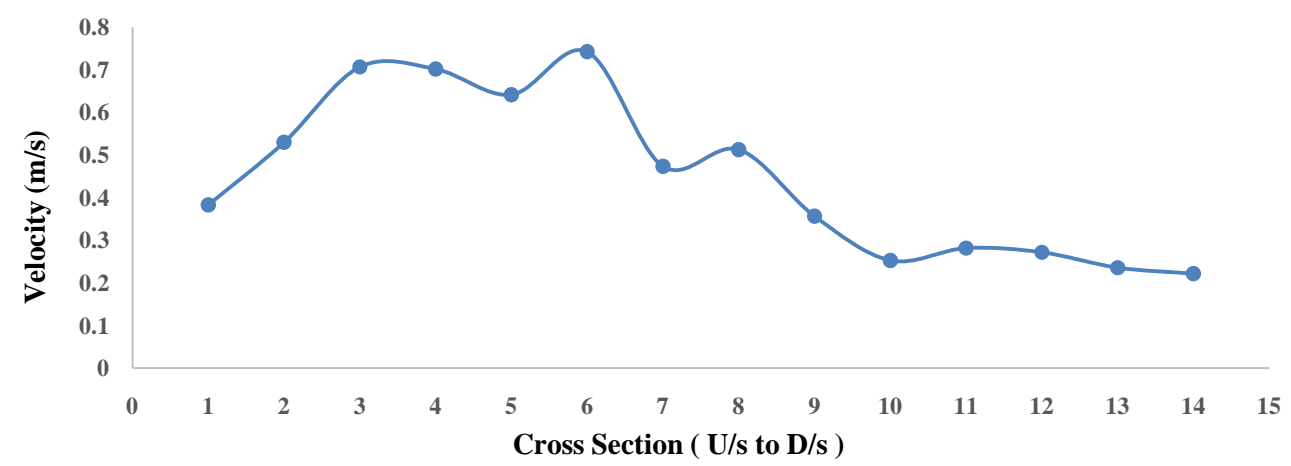

(c)

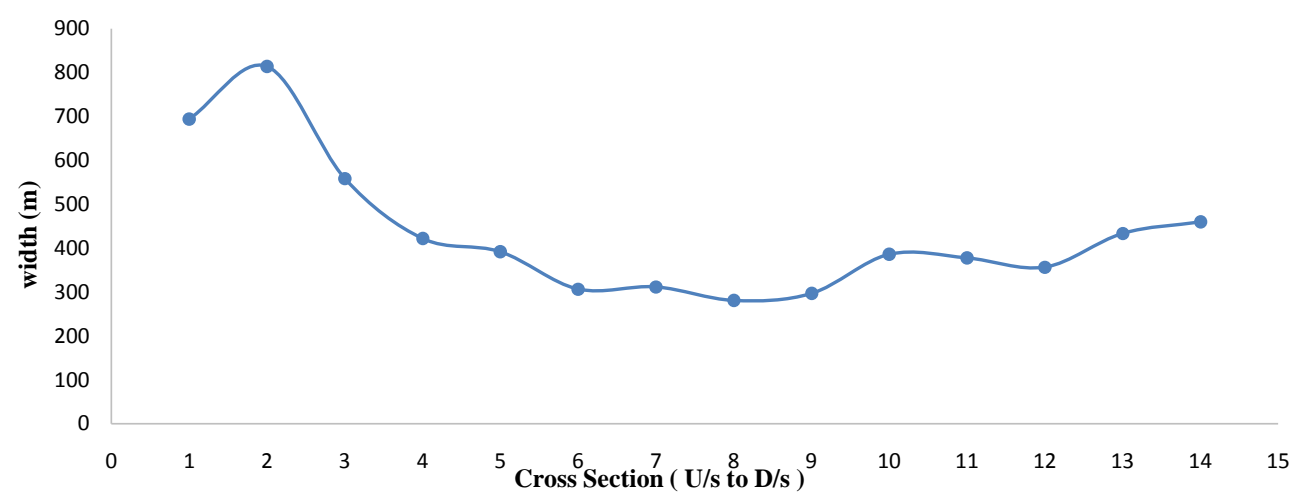

(d)

Figure 4. (a) Depth Variation along with cross section from M-14 to M-1; (b) Width variation with cross section from M-14 to $\mathrm{M}-1$; (c) Velocity distribution with cross section from M-14 to M-1; (d) Discharge variation with cross section from M-14 to $\mathrm{M}-1$. 
Leaving the starting upstream station (M-14) the width of river is almost having decreasing trend till (M-6) cross section as shown in Figure 4(b). This shows a varying average depth and average width of flow at its different cross section due to its meandering and sinusoidal characteristics.

Generally long profile gradient of river is decreases in downstream due to increasing hydraulic radius (cross section efficiency) but here at Varanasi bend the velocity is increasing up to M-12 cross section after which the inconsistent bend for velocity obtained although from the M-7 cross section the average velocity of flow is continuously decreasing as shown in Figure 4(c). The above theory of increasing velocity in downstream seems to be not valid for River Ganga at Varanasi bend. The decreasing of velocity had resulted by the increasing the depth of flow in downstream consistency. Discharge variation with the cross sections is also shown in Figure 4(d).

Any stream with having changing volume may assume a meandering course, alternatively eroding sediments from the outside of a bend and depositing them on the inside. This meandering characteristic and sinuosity along Ganga river course had showed non uniformity in the river width and uneven depth of water. The main cause of overall these parameters is heavy rainfall from which the runoff in term of river flow depends. The rainfall intensity mainly governs the amount of erosion and the geological parameters decide the deposition of eroded sediment in the river which leads to variation in the geometry of any river. Human activity is also the indisputable cause for high flow which involved of building of impervious structures, deforestation, and caused to the higher surface runoff and decrease the time of concentration by which even on small rainfall leads to change in depth of river flow. On the other hand, forestation such as pine tree and other tree which can increase infiltration so that time of peak can delay and its harmful effects can be reduced. To minimize the impact of surface runoff directly to the river flood mitigations concept should be undertaken and another river training work to be adopted along the Ganga River in order to minimize erosion as well as sedimentation enter to the river.

\section{Conclusions}

The monitoring of discharge and velocity distribution was conducted using consistent protocols designed to ensure the scientific validity of the data. These stream flow datasets will aid in the management of water resources in a sustainable manner for the benefit of water users and the environment.

A multiple linear regression model was developed by using the measured discharge, depth and velocity through ADCP of Varanasi bend of river Ganga. The regression equation shows a high correlation between the discharge, depth and velocity parameters with the $\mathrm{R}^{2}$ value of 0.8624 . Among the validation set of 31 data's, 9 data's of discharge were in the range of $100 \mathrm{~m}^{3} / \mathrm{s}$ and out of which 6 data's gave more errors, as well as the average velocity lies in the range of $0.101 \mathrm{~m} / \mathrm{s}$ to $0.279 \mathrm{~m} / \mathrm{s}$ in validation set which gave more errors in validation of model. The proposed model is validated for the average velocity greater than $0.279 \mathrm{~m} / \mathrm{s}$ up to $0.899 \mathrm{~m} / \mathrm{s}$. The developed model also shows variation when the depth of flow is less than $5 \mathrm{~m}$, so this model is suitable for the depth above $5 \mathrm{~m}$ up to the maximum of $19.98 \mathrm{~m}$ at the Varanasi bend of River Ganga. The equations developed for this study are not applicable for ungaged sites in which the basin characteristics are not in the range of those used to develop the regression equations.

\section{Acknowledgements}

Authors are thankful to Department of Civil Engineering, Indian Institute of technology (BHU) for providing the infrastructure and computational facilities to complete this work.

\section{References}

[1] Engeland, K. and Hisdal, H. (2009) A Comparison of Low Flow Estimates in Ungauged Catchments Using Regional Regression and the HBV-Model. Water Resources Management, 23, 2567-2586. http://dx.doi.org/10.1007/s11269-008-9397-7

[2] Eslamian, S., Ghasemizadeh, M., Biabanaki, M. and Talebizadeh, M. (2010) A Principal Component Regression Method for Estimating Low Flow Index. Water Resources Management, 24, 2553-2566. http://dx.doi.org/10.1007/s11269-009-9567-2

[3] Tayfur, G. and Singh, V.P. (2011) Predicting Mean and Bank Full Discharge from Channel Cross Sectional Area by Expert and Regression Methods. Water Resources Management, 25, 1253-1267. http://dx.doi.org/10.1007/s11269-010-9741-6 
[4] Zhu, Y.-Y. and Zhou, H.-C. (2009) Rough Fuzzy Inference Model and Its Application in Multi-Factor Medium and Long-Term Hydrological Forecast. Water Resources Management, 23, 493-507. http://dx.doi.org/10.1007/s11269-008-9285-1

[5] Akbari, F.M., Afshar, A. and Sadrabadi, M.R. (2009) Fuzzy Rule Based Models Modification by New Data: Application to Flood Flow Forecasting. Water Resources Management, 23, 2491-2504. http://dx.doi.org/10.1007/s11269-008-9392-z

[6] Chen, C.H., Chou, F.N.-F. and Chen, B.P-.T. (2010) Spatial Information-Based Back-Propagation Neural Network Modeling for Outflow Estimation of Ungauged Catchment. Water Resources Management, 24, 4175-4197. http://dx.doi.org/10.1007/s11269-010-9652-6

[7] Walter, C. and Tullos, D.D. (2010) Downstream Channel Changes after a Small Dam Removal: Using Aerial Photos and Measurement Error for Context; Calapooia River, Oregon. River Research and Applications, 26, 1220-1245. http://dx.doi.org/10.1002/rra.1323

[8] Wharton, G., Arnell, N.W., Gregory, K.J. and Gurnell, A.M. (1989) River Discharge Estimated from River Channel Dimensions. Journal of Hydrology, 106, 365-376. http://dx.doi.org/10.1016/0022-1694(89)90080-2

[9] Wharton, G. and Tomlinson, J.J. (1999) Flood Discharge Estimation from River Channel Dimensions: Results of Applications in Java, Burundi, Ghana and Tanzania. Hydrological Sciences Journal, 44, 97-111. http://dx.doi.org/10.1080/02626669909492205

[10] Bhatt, V.K. and Tiwari, A.K. (2008) Estimation of Peak Stream Flows through Channel Geometry. Hydrological Sciences Journal, 53, 401-408. http://dx.doi.org/10.1623/hysj.53.2.401

[11] Andersson, L., Wilk, J., Todd, M.C., Hughes, D.A. and Earle, A. (2006) Impact of Climate Change and Development Scenarios on Flow Patterns in the Okavango River. Journal of Hydrology, 331, 43-57. http://dx.doi.org/10.1016/j.jhydrol.2006.04.039

[12] Kamarudin, M.K.A., Toriman, M.E., Mastura, S., Idrisand, M. and Jamil, N.R. (2009) Temporal Variability on Lowland River Sediment Properties and Yield. American Journal of Environmental Sciences, 5, 657-663. http://dx.doi.org/10.3844/ajessp.2009.657.663

[13] Jung, I.W., Chang, H. and Moradkhani, H. (2011) Quantifying Uncertainty in Urban Flooding Analysis Considering Hydro-Climatic Projection and Urban Development Effects. Hydrology and Earth System Sciences, 15, 617-633. http://dx.doi.org/10.5194/hess-15-617-2011

[14] Hoyle, J., Brooks, A. and Spencer, J. (2012) Modelling Reach-Scale Variability in Sediment Mobility: An Approach for Within-Reach Prioritization of River Rehabilitation Works. River Research and Applications, 28, 609-629. http://dx.doi.org/10.1002/rra.1472

[15] Schwendel, A.C., Fuller I.C. and Death, R.G. (2012) Assessing DEM Interpolation Methods for Effective Representation of Upland Stream Morphology for Rapid Appraisal of Bed Stability. River Research and Applications, 28, 567584. http://dx.doi.org/10.1002/rra.1475

[16] Chitale, S.V. (1970) River Channel Patterns. Journal of Hydraulic Division American Society Civil Engineering, 96, 201-221.

[17] Allen, J.R.L. (1982) Sedimentary Structures, Their Character and Physical Basis. Elsevier Science, New York, 633.

[18] Howard, A.D. (1992) Modeling Channel Migration and Floodplain Sedimentation in Meandering Streams. In: Carling, P. and Petts, G.E., Eds., Lowland Floodplain Rivers: Geomorphological Perspectives, John Wiley, Hoboken, 41-41. 